\begin{tabular}{|l|c|c|c|c|c|}
\hline J. Tek. Ling & Vol. 13 & No. 1 & Hal. $67-74$ & Jakarta, Januari 2012 & ISSN 1441-318X \\
\hline
\end{tabular}

\title{
Dampak Eutrofikasi Terhadap Struktur Komunitas dan Evaluasi Metode Penentuan Kelimpahan Fitoplankton
}

\author{
Yudhi Soetrisno Garno \\ Peneliti Utama Bidang LImnologi \\ di Pusat Teknologi Lingkungan BPPT \\ yusoegarno@scientist.com
}

\begin{abstract}
Abstrak
Pada umumnya peneliti menentukan status kualitas perairan menggunakan data yang diperoleh dengan plankton-net. Data tersebut tidak menceminkan kepadatan dan struktur komunitas fitoplankton yang sebenarnya. Oleh karena itu data tersebut kurang layak untuk menganalisis status kualitas perairan. Artikel ini menyampaikan hasil kajian kelimpahan fitoplankton di perairan tawar dan laut, yang diperoleh dengan dan tanpa menggunakan plankton-net. Kepadatan yang diperoleh dengan planktonnet menghasilkan nilai yang jauh lebih kecil dari kepadatan yang diperoleh tanpa menggunakan plankton-net. Ini mengisyaratkan bahwa untuk menganalisis status kualitas air, lebih layak menggunakan data yang diperoleh dengan tanpa plankton-net
\end{abstract}

kata kunci: fitoplankton, plankton-net, nutrien, eutrofikasi, struktur komunitas.

\begin{abstract}
In general, researchers determine the status of water quality using data obtained with a plankton-net. The data do not reflect the density and the actual structure of phytoplankton communities. Therefore, the data is not feasible to analyze the water quality status. This article present the results of the study the abundance of phytoplankton in freshwater and marine, which obtained with and without using a plankton-net. Density obtained with a plankton-net produce values that are much smaller than the density obtained without using a plankton-net. This implies that in order to analyze the status of water quality, is more feasible to use data obtained with the no-net plankton
\end{abstract}

key words: phytoplankton, plankton-net, nutrients, eutrophication, the community structure.

\section{PENDAHULUAN}

\subsection{Eutrofikasi dan dampaknya}

Tanpa disadari, badan-badan air di perairan umum disekitar kita terutama yang relatif tergenang seperti situ, danau dan waduk bahkan pantai tertutup sedikit demi sedikit berubah warna menjadi kehijauhijauan. Para pakar ekologi perairan sepakat bahwa fenomena tersebut disebabkan oleh peningkatan kepadatan fitoplankton yang diakibatkan oleh peningkatan konsentrasi nutrien/hara terlarut dalam badan air, yang dapat berasal dalam dan luar ekosistem. Dari dalam ekosistem, peningkatan nutrien berasal dari dekomposisi organik (detritus \& kotoran/ekskresi) dan regenerasi nutrien oleh zooplankton, sedangkan dari luar ekosistem nutrien masuk ke badan air melalui berbagai bahan buangan (limbah) baik yang disengaja ataupun tidak. 
Fitoplankton adalah tumbuhan mikroskopik yang hidup melayang-layang dalam air. Fitoplankton terdiri dari divisi chrysophyta (diatom), chlrorophyta dan cyanophyta. Pada umumnya chlorophyta dan cyanophyta mudah ditemukan pada komunitas plankton perairan tawar sedangkan chrysophyta dapat ditemukan diperairan tawar dan asin. Di perairan umum, komunitas fitoplankton umumnya didominasi oleh jenis fitoplankton yang berukuran lebih kecil dari $10 \mu \mathrm{m}^{(1)}$

Keberadaan dan kelimpahan suatu jenis fitoplankton di perairan umum sangat ditentukan oleh sifat fisik dan kimia air, khususnya kandungan nutrien badan air tersebut ${ }^{(2.3,4)}$. Nutrien merupakan unsur kimia yang diperlukan alga (fitoplankton) untuk pertumbuhannya. Untuk pertumbuhannya, meskipun sebagian besar hanya dibutuhkan dalam jumlah sangat sedikit (nutrien mikro) namun fitoplankton membutuhkan paling sedikit 19 macam nutrien.

Sampai pada tingkat konsentrasi tertentu, peningkatan konsentrasi nutrien dalam badan air akan meningkatkan produktivitas perairan, karena nutrien yang larut dalam badan air langsung dimanfaatkan oleh fitoplankton untuk pertumbuhannya sehingga populasi dan kelimpahannya meningkat. Peningkatan nutrien yang berkelanjutan dalam konsentrasi yang tinggi pada akhirnya akan menyebabkan badan air menjadi sangat subur atau eutrofik dan menimbulkan gangguan (dampak negatif) bagi badan air tersebut yakni terjadinya . Proses peningkatan kesuburan air yang berlebihan yang disebabkan oleh masuknya nutrien dalam badan air, terutama fosfat inilah yang disebut eutrofikasi.

Publikasi yang ada menyatakan bahwa kandungan fosfor $>0,010 \mathrm{mgP} / \mathrm{l}$ dan nitrogen $>0,300 \mathrm{mgN} / \mathrm{l}$ dalam badan air baik keduaduanyanya ataupun salah satunya akan merangsang fitoplankton untuk tumbuh dan berkembang-biak dengan pesat, sehingga terjadi blooming ${ }^{(5)}$.

Kilham dan Kilham. ${ }^{(6)}$ mengemukakan bahwa setiap jenis fitoplankton mempunyai respon yang berbeda terhadap perbandingan jenis nutrien yang ada utamanya perbandingan konsentrasi nitrogen, fosfor dan silika dalam badan air. Fenomena inilah yang mendorong beberapa pakar ekologi menyimpulkan bahwa dominasi suatu jenis fitoplankton lebih ditentukan oleh perbandingan jenis nutrien yang terlarut dalam badan air(6) . Hal ini dikarenakan fitoplankton yang sesuai dengan perbandingan unsur hara dalam badan air akan tumbuh dengan baik sehingga menjadi dominan, sedangkan fitoplankton yang tak sesuai dengan perbandingan unsur hara yang ada akan mati atau hidup tertekan tidak berkembang.

Selain oleh perbandingan unsur hara, dominasi fitoplankton dalam suatu badan air juga dipengaruhi oleh zooplankton yang menjadi pemangsa/pemakan utamanya. Beberapa jenis fitoplankton diketahui tidak dapat dimakan oleh zooplankton karena bentuk morpologi dan fisiologi fitoplankton $(7,8,9,10)$ ukuran, komposisi dan mekanisme makan zooplankton $(11,12,13)$ serta faktor abiotik lainnya. Terakhir diketetahui pula bahwa dalam kondisi persediaan makanan (fitoplankton) berlimpah dan beragam; zooplankton mampu melakukan pemilihan terhadap jenis, bentuk dan ukuran makanan yang hendak dimakan ${ }^{(8)}$. Fitoplankton yang tersisa dalam badan air, baik karena tidak dapat dimakan maupun tidak disukai oleh zooplankton inilah yang pada gilirannya akan menjadi dominan ${ }^{(8)}$ sesuai dengan daya adaptasi mereka pada perbandingan unsur-unsur hara yang tersedia dalam badan air tersebut.

Dengan demikian maka interaksi kompleks antara nutrien, fitoplankton dan zooplankton tersebut menyebabkan badan air yang mengalami eutrofikasi pada akhirnya akan didominasi oleh sejenis fitoplankton tertentu yang pada umumnya tidak bisa dimakan oleh fauna air terutama zooplankton dan ikan; termasuk karena beracun. Sebagai contoh yang nyata dari fenomena ini adalah dominasi Mycrocistis sp di waduk-waduk 
Saguling, Cirata dan Jatiluhur dan dominasi Pyrodinium bahamense, lexandrium spp. dan Gymnodinium spp. di perairan pantai/ pesisir waktu terjadi "red-tide".

Selain merugikan dan mengancam keberlanjutan fauna akibat dominasi fitoplankton yang tidak dapat dimakan dan beracun; blooming yang menghasilkan biomasa (organik) tinggi juga merugikan fauna; karena fenomena blooming selalu diikuti dengan penurunan oksigen terlarut secara drastis akibat pemanfaatan oksigen yang berlebihan untuk dekomposisi biomasa (organik) yang mati. Konsentrasi oksigen terlarut yang rendah apalagi jika sampai batas nol akan menyebabkan ikan dan fauna lainnya tidak bisa hidup dengan baik dan mati. Selain menekan oksigen terlarut proses dekomposisi tersebut juga menghasilkan gas beracun seperti $\mathrm{NH}_{3}$ dan $\mathrm{H}_{2} \mathrm{~S}$ yang pada konsentrasi tertentu dapat membahayakan fauna air, termasuk ikan.

Uraian tersebut diatas mengungkapkan bahwa dampak negatif dari pencemaran nutrien atau eutrofikasi timbul berkenaan dengan terjadinya 2 (dua) fenomena yang berhubungan erat dengan kepadatan fitoplankton; yakni: (i) dominasi fitoplankton yang tidak dapat dimakan dicerna dan atau beracun, dan (ii) blooming fitoplankton yang dapat mengakibatkan deplesi oksigen terlarut dan munculnya gas beracun. Oleh karena itu maka sudah tepat jika kepadatan fitoplankton telah dijadikan salah satu parameter utama dalam menganalisis dampak pencemaran nutrien terhadap kualitas perairan.

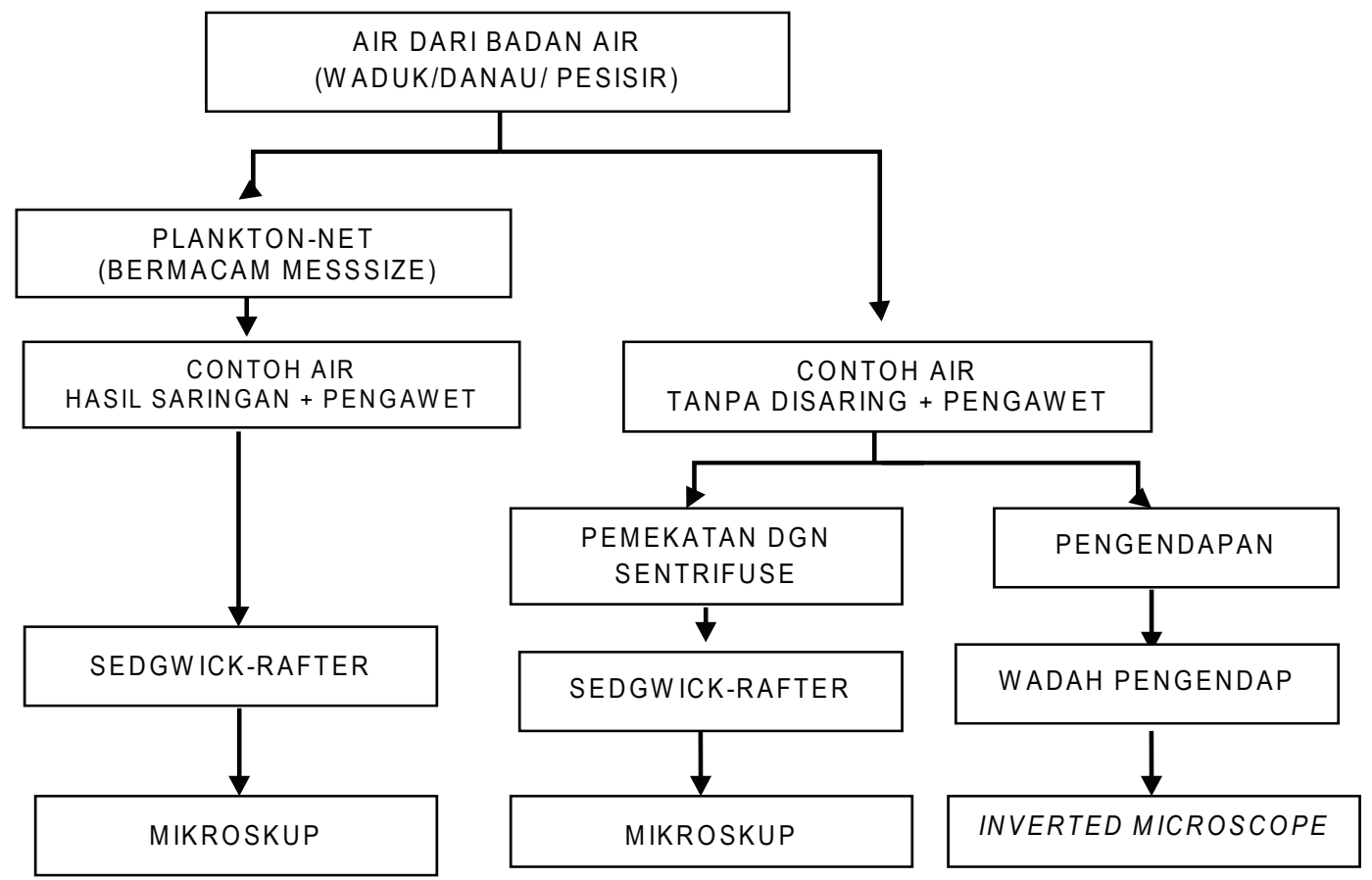

Gambar 1 Flow-chart penentuan kepadatan fitoplankton

NB: Dari flow chart diatas dapat dikelompokkan 3 (tiga) metode (M) penentuan kepadatan fitoplankton yakni:

1. C-1: penentuan melalui alur plankton-net $\rightarrow$ sedgwick-rafter $\rightarrow$ mikroskup.

2. C-2: penentuan melalui alur tidak disaring $\rightarrow$ sedgwick-rafter $\rightarrow$ mikroskup.

3. C-3: penentuan melalui alur tidak disaring $\rightarrow$ pengendapan $\rightarrow$ inverted microscope 


\subsection{Penentuan Kepadatan Fitoplankton}

Secara umum penentuan kepadatan fitoplankton dilakukan dengan melalui 2 (dua) tahap yakni :

a. Pengumpulan contoh (sample) air yang merupakan kegiatan di lapangan yang meliputi pengambilan air, dan pengawetan air dengan lugol/formalin dalam botol sampel.

b. Analisis dengan mikroskup yang merupakan kegiatan di laboratorium yang meliputi persiapan preparat (sedgwick-rafter/sentrifuse/pengendap) dan pengamatan di bawah mikroskup, yang diikuti dengan identifikasi dan penghitungan.

Secara detail pentahapan penentuan fitoplankton tergambar pada Gambar-1. Gambar-1 menunjukkan bahwa secara umum penentuan kelimpahan fitoplankton dapat dilakukan dengan 3 cara yakni cara-1 (C-1), cara-2 (C-2) dan cara-3 (C-3) seperti pada catatan dalam Gambar-1.

Literatur yang ada mengungkapkan bahwa pada umumnya peneliti menentukan kelimpahan fitoplankton dengan cara-1, yakni mengumpulkan contoh-air dengan menyaring air memakai plankton-net dengan mesh size berbeda-beda. Adnan menggunakan plankton-net dengan mesh size $20 \mu \mathrm{m}^{(14) ;}$ Sidabutar dengan mesh size $64 \mu \mathrm{m}^{(15)}$; Effendi dengan mesh size80 $\mu \mathrm{m}$ (16) dan Praseno and Adnan dengan mesh size. $110 \mu \mathrm{m}^{(17)}$.

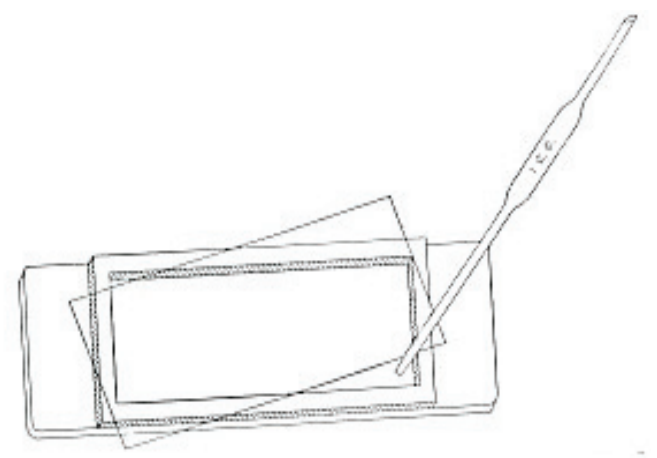

Gambar 2. Sedgwick-Rafter

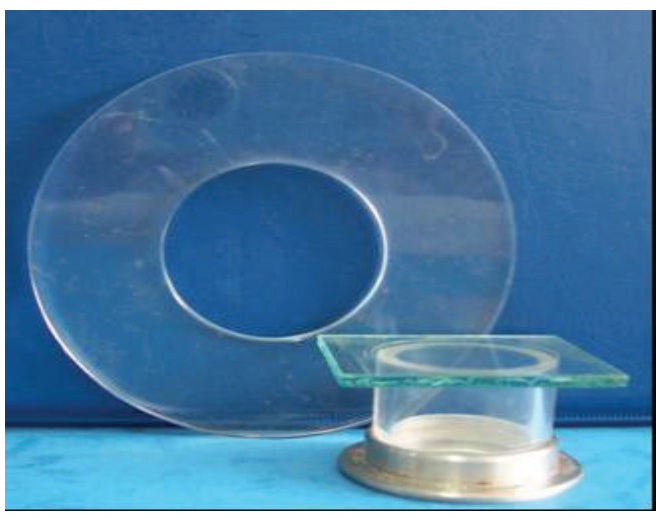

Gambar-3. Pengendap fitoplankton bervolume $10 \mathrm{ml}$

Di Laboratorium, contoh air yang telah diawetkan dengan formalin/lugol di masukan ke dalam preparat "Sedwgwick-Rafter"yang bervolume $1 \mathrm{ml}$ dan kemudian ditempatkan dibawah mikroskup, diidentifikasi dan dihitung. Hasil penghitungan dengan saringan tersebut yang pertama pasti terjadi adalah yang terhitung hanyalah fitoplankton yang tidak lolos saringan sehingga kepadatan yang dihasilkan adalah bukan kepadatan sebenar nya. Kedua adalah mengingat struktur fitoplankton berbeda disetiap tempat dan waktu maka hasil penghitungan disatu badan air tidak bisa dibandingkan dengan badan air lain, apalagi jika ukuran saringan berbeda. Fenomena tersebut menimbulkan pertanyaan "pantaskan datadata tersebut digunakan untuk menganalisis hubungan kepadatan fitoplaknton dengan dinamika nutrien terlarut dan zooplankton" atau "dijadikan dasar analisis status kualitas perairan", apalagi dijadikan dasar pengambilan keputusan sistem pengelolaan lingkungan suatu perairan.

Berkenaan dengan pertanyaanpertanyaan tersebut maka penulis menyampaikan beberapa hasil kajian penentuan kepadatan fitoplankton dengan 3 cara yang ada yakni Cara-1, Cara-2 dan Cara-3, dengan harapan diperoleh data yang lebih mencerminkan kondisi sebenarnya 
badan air saat pengambilan contoh air sehingga lebih layak pemanfaatannya dan lebih mendekati kebenaran hasil analisanya.

\section{Kajian Evaluasi Metode Penentuan Fitoplankton.}

Agar dapat dipergunakan secara universal, maka kajian dilakukan di jenis perairan yakni perairan tawar dan perairan asin. Diperairan tawar dilakukan di Waduk Saguling dan Cirata pata Tahun 1999 dengan menggunkan metode C-1 dan C-3; sedangkan di perairan laut dilakukan di Pulau Kelapa pada Tahun 1999 dengan menggunakan $\mathrm{C}-2$ dan $\mathrm{C}-3$

\section{HASIL DAN PEMBAHASAN}

\subsection{Perairan Tawar}

Hasil penentuan kepadatan fitoplankton di perairan waduk Saguling dan Cirata dengan menggunakan C-1 dan C-3 disampaikan pada Tabel-1. Tabel-1 mengungkapkan bahwa nilai kepadatan hasil penentuan dengan $\mathrm{C}-1$ jauh lebih kecil dari hasil penentuan dengan C-3. Di waduk Saguling nilai kepadatan fitoplankton dengan C-1 hanya menghasilkan kelimpahan 0,09-0,47\% dengan C-3, sedangkan di waduk Cirata kepadatan fitoplankton yang ditentukan dengan C-1 hanya $0,15-60 \%$ kepadatan yang ditentukan dengan C-3. Selain nilai kepadatan yang sangat under estimate disetiap waduk tersebut Garno ${ }^{19,20)}$ juga mengungkapkan bahwa penentuan kepadatan fitoplankton dengan C-1 menghasilkan jenis fitoplankton dominan yang berbeda dengan penentuan kepadatan fitoplankton dengan C-3. Perbedaan struktur komunitas inilah yang menyebabkan prosentase C1 terhadap C-3 di Waduk Saguling sangat berbeda dengan di Cirata ${ }^{19,20)}$.

Kedua perbedaan hasil C-1 dan C-3 ini sudah pasti akan memberikan arahan yang salah pada proses penyusunan, pemilihan dan penentuan bentuk pengelolaan lingkungan yang akan digunakan. Ini berarti bahwa perhitungan dengan C-1 hanya dapat digunakan untuk identifikasi jenis fitoplankton ${ }^{(1)}$. Oleh karena itu kembali penulis menegaskan bahwa hasil perhitungan fitoplankton dengan $\mathrm{C}$-1 sangat tidak layak untuk dijadikan dasar analisis status kualitas perairan, apalagi dijadikan dasar pengambilan keputusan sistem pengelolaan lingkungan suatu perairan.

Tabel-1. Kepadatan Fitoplankton di waduk Saguling dan Cirata ditentukan dengan M-1 dan M-3.

\begin{tabular}{|c|c|c|c|c|c|c|c|c|c|}
\hline \multirow{2}{*}{ LOKASI } & \multicolumn{6}{|c|}{ Kepadatan Fitoplankton di tempat pengambilam contoh air } \\
\cline { 2 - 10 } & \multicolumn{2}{|c|}{1} & \multicolumn{2}{|c|}{2} & \multicolumn{2}{|c|}{3} & \multicolumn{3}{c|}{ C-1/C-3 } \\
\hline & C-3 & C-1 & C-3 & C-1 & C-3 & C-1 & 1 & 2 & 3 \\
\hline $\begin{array}{c}\text { W. Saguyling } \\
\text { Juni 1999 }\end{array}$ & 16.946 & 14.42 & 39.655 & 65.57 & 24.127 & 21.29 & 0,09 & 0,17 & 0,09 \\
\hline $\begin{array}{c}\text { W. Saguling, } \\
\text { Juli '1999 }\end{array}$ & 20.490 & 80.04 & 13.691 & 64.51 & 13.279 & 35.29 & 0,40 & 0,47 & 0,27 \\
\hline $\begin{array}{c}\text { W. Cirata, } \\
\text { Juni 1999 }\end{array}$ & 22.080 & 76.60 & 38.080 & 89.90 & 36.560 & 140,0 & 0,35 & 0,24 & 0,38 \\
\hline $\begin{array}{c}\text { W. Cirata, } \\
\text { Juni 1999 }\end{array}$ & 43.840 & 77,30 & 26.240 & 39.90 & 32.400 & 159,0 & 0,18 & 0,15 & 0,49 \\
\hline $\begin{array}{c}\text { W. Cirata, Juli } \\
\text { 1999 }\end{array}$ & 29.040 & 87.70 & 38.720 & 140,0 & 25.900 & 105,0 & 0,30 & 0,36 & 0,41 \\
\hline
\end{tabular}




\subsection{Perairan Laut}

Hasil penentuan kepadatan fitoplankton di perairan pulau Kelapa dengan menggunakan C-2 dan C-3 disampaikan pada Tabel-2. Tabel-2 mengungkapkan bahwa nilai kepadatan hasil penentuan dengan C-2 lebih kecil yakni hanya berkisar antara $2,4-18,5 \%$ dari hasil penentuan dengan C-3. Fenomena ini terjadi diduga karena penggunaan centrifuge untuk pemekatan sulit membuahkan hasil yang sempurna, karena banyak fitoplankton terbuang, sehingga setelah dihitung menghasilkan kelimpahan yang lebih kecil dari C-3. Oleh karena itulah Garno ${ }^{21)}$ menyimpulkan bahwa penentuan dengan $\mathrm{C}-2$ menghasilkan nilai kepadatan yang under-estimate. Selain karena pemekatan yang tidak sempurna; "under-estimate" pada C-2 juga dapat terjadi karena penggunaan sedwick rafter yang sulit untuk memfokuskan semua fitoplankton yang ada dibawah objektif.

\section{KESIMPULAN DAN SARAN}

Mencermati hasil kedua kajian tersebut diatas, disimpulkan bahwa penentuan kepadatan fitoplankton dengan C-1 menghasilkan nilai kepadatan yang sangat under-estimate; sedangkan dengan C-2 meskipun menghasilkan nilai yang under estimate namun masih lebih wajar dari nilai penentuan kepadatan dengan C-1. Ini berarti bahwa untuk keperluan analisis status kualitas air, data hasil penentuan kelimpahan dengan C-3 lebih layak daripada dengan C-2 dan $\mathrm{C}-1$, dan dengan data C-2 lebih layak daripada C-1.

Dengan hasil dan kesimpulan seperti tersebut diatas, maka penulis menyarankan pada semua peneliti dan praktisi dibidang ekologi perairan di Indonesia untuk :

a. menggunakan data-data fitoplankton yang pengambilan sampelnya dengan penyaringan ( $\mathrm{C}-1)$ hanya untuk mengetahui jumlah jenis fitoplankton yang ada (identifikasi),

b. tidak menggunakan data-data tersebut pada poin (a) untuk analisis status kualitas lingkungan perairan termasuk penentuan dominansi jenis.

c. mulai menggunakan penentuan kepadatan fitoplankton dengan penganbilan contoh air tanpa penyaringan; diikuti dengan pengendapan dan penghitungan dibawah inverted mikroskoop.

Tabel-2. Kepadatan Fitoplankton di pulau Kelapa ditentukan dengan C-2 dan C-3

\begin{tabular}{|l|r|r|r|r|r|r|r|r|r|}
\hline \multirow{2}{*}{ L O K A S I } & \multicolumn{6}{|c|}{ Kepadatan Fitoplankton (ind./ml) di tempat pengambilam contoh air } \\
\cline { 2 - 10 } & \multicolumn{2}{|c|}{ Pagi } & \multicolumn{2}{c|}{ Siang } & \multicolumn{2}{c|}{ Sore } & \multicolumn{3}{c|}{ C1/C-3 } \\
\cline { 2 - 10 } & C-3 & C-2 & C-3 & C-2 & C-3 & C-2 & 1 & 2 & 3 \\
\hline P. Kelapa 7-1-1999 & 727.3 & 38.19 & 1.018 .2 & 29.09 & 145.44 & 27.28 & 5,3 & 2,9 & 18,5 \\
\hline P. Kelapa, 28-1-1999 & 654.5 & 41.83 & 1.745 .4 & 41.82 & 1.454 .5 & 36.37 & 6,5 & 2,4 & 2,5 \\
\hline P. Kelapa, 22 -4-1999 & 1.163 .6 & 192.7 & 1.745 .4 & 85.46 & 1.599 .9 & 147.84 & 16,7 & 4,9 & 9,3 \\
\hline
\end{tabular}




\section{DAFTAR PUSTAKA}

1. Garno, Y.S. 1998. "Peran Plankton Net pada pemisahan dan strukturisasi komunitas Fitoplankton". BPP Teknologi, Jakarta, 374-392.

2. Hutchinson, G.E. 1944: "Limnological studies in Connecticut. 7. A. Critical examination of supposed relationship between phytoplankton peridiocity and chemical changes in lake waters". Ecology 25. 3-25.

3. Margalef, R. 1958:."Temporal succession and spaital heterogeneity in phytoplankton" In A.A. BuzzatiTraverso (ed.), Perspective in Marine Biology Univ. Calofornia Press. 323349.

4. Reynolds, C.S. 1989: "Physical deteminants of phytoplankton succesion" In U. Sommer (ed.) Plankton ecology. Springler-Verlag. 9-51.

5. Hendersen B. and H.R. Markland "Decaying Lakes-The Origins and Control of Cultural Eutrofication", John \& Willey Sons Ltd. New York. Brisbane, Toronto, Singapura, 1987.

6. Kilham, S.S, dan P. Kilham 1978:"Natural community bioasaays: Predictions of result based on nutrien physiology and competition", Int. Ver. Theor. Angew. Limnol. Verh., 20, 68-74

7. Horn, W., 1981:"Phytoplankton losses due to zooplankton grazing in dringking water reservoir", Int. Revue ges. Hidrobiol., 66, 787-810.

8. Garno, Y. S 1993: "Eligibility of Several Phytoplankton species by Simocephalus vetulus", Directorate for The Human Settlement and Environmental Technology, BPP Teknologi, 107-113

9. Geller,, W. 1975: "Food ingestion of Daphnia pulex as a punction of food concentration, temperatur, animals, body length and hunger", Arch. Hydrobiol. Suppl., 48, 47-107Bold, H.C dan M.J. Wyne, 1978: Introduction to the Algae: Structure and Reproduction. New Jersey: Prentice-Hall Inc. 32.

10. Downing, J. A, and R.H. Petter, "The effect of body size and food concentration on the in-situ filtering rate of Sida crystalina , Limnol. Ocanogr., 25, 1980, 883-896.

11. DeMott, W.R., 1982: “Feeding selectivities and relatives ingestion rates of Daphnia and Bosmina , Limno., Oceanogr. 27, 518-527.

12. Frost, B.W., 1980: "Grazing" In I. Morris (ed.): The physiological ecology of phytoplankton. Blackwell Scientific, Oxford: 465-486.

13. James M.R, and D.J. Forsynth 1990" Zooplankton-phytoplankton interaction in a eutrophic lake. J. Plankton Res., 12, 455-472

14. Adnan Q. (1998). Kelimpahan Fitoplankton di Estuarin Muara Angke Teluk Jakarta tahun 1995. Direktorat Teknologi Pemukiman dan Lingkungan Hidup, BPPT, Jakarta, 254-265.

15. Sidabutar, T., (1996): Kondisi Plankton dan Hidrologi di Perairan Seram Barat dan Ssekitarnya pada Musim Timur, Seminar Maritim Indonesia. BPP Teknologi-Wanhankamnas, Makkasar,: 283-297.

16. Effendi M (1998). Penelitian Kelimpahan Biota Perairan antara Pulau Tarakan dan P. Bunyu, BPP Teknologi, Jakarta, 351-363.

17. Praseno D.P and Adnan Q, (1996): Phytoplankton Community and Abundance In Some Estuaries of The Northern Coast of Java. Workshop on Making Efficient Use on Marine Environmental Monitoring for Supporting Sustainable Development. Directorate for the Human Settlement and Environmental Technology, BPPT, Jakarta, 17-24.

18. Praseno D.P and Adnan Q, (1996): Phytoplankton Community and Abundance In Some Estuaries of The Northern Coast of Java. Workshop 
on Making Efficient Use on Marine Environmental Monitoring for Supporting Sustainable Development. Directorate for the Human Settlement and Environmental Technology, BPPT, Jakarta, 17-24.

19. Garno, Y.S (1999) : Studi evaluasi Penggunaan Plankton - net pada Sampling Fitoplankton Dalam Analisis Status Lingkungan Ekosistem Perairan. Jurnal Sains dan Teknologi Indonesia “Edisi Khusus". BPPT 1(5) : 146-155.
20. Garno,Y.S (2000) : Penerapan Metode pengendapan pada Penentuan Kelimpahan Fitoplankton Perairan Pesisir dan Laut. JSTI-BPPT, "Edisi Khusus". 4(5): 53-60.

21. Garno,Y.S (2002) : Aplikasi Metode Pengendapan Pada Analisis Fitoplankton dan Tingkat Kesuburan Waduk Saguling. J.Tekling, 1(2) : 126134. 